\title{
Optical coherence tomography for vulnerability assessment of sandstone
}

\author{
Elizabeth Bemand and Haida Liang* \\ School of Science and Technology, Nottingham Trent University, Clifton Lane, Nottingham NG11 8NS, UK \\ *Corresponding author: haida.liang@ntu.ac.uk
}

Received 5 February 2013; revised 11 April 2013; accepted 17 April 2013;

posted 19 April 2013 (Doc. ID 184896); published 9 May 2013

\begin{abstract}
Sandstone is an important cultural heritage material, in both architectural and natural settings, such as neolithic rock art panels. The majority of deterioration effects in porous materials such as sandstone are influenced by the presence and movement of water through the material. The presence of water within the porous network of a material results in changes in the optical coherence tomography signal intensity that can be used to monitor the wetting front of water penetration of dry porous materials at various depths. The technique is able to detect wetting front velocities from $1 \mathrm{~cm} \mathrm{~s}^{-1}$ to $10^{-6} \mathrm{~cm} \mathrm{~s}^{-1}$, covering the full range of hydraulic conductivities likely to occur in natural sandstones from pervious to impervious. (C) 2013 Optical Society of America

OCIS codes: (110.4500) Optical coherence tomography; (120.4290) Nondestructive testing.

http://dx.doi.org/10.1364/AO.52.003387
\end{abstract}

\section{Introduction}

A key problem in cultural resource management is identifying those artifacts in need of immediate conservation by generating quantitative data for decision makers [1]. Capillary rise of groundwater and associated transport of mineral salts and other pollution into the porous network of stones has been reported as a significant cause of weathering damage at many cultural heritage sites [2, 3 ] .

Most deterioration effects in porous sandstone materials arise as a direct or indirect consequence of water [4]. Deterioration can be as a result of chemical, physical, and biological processes. The movement of water through the stone can result in solutional material loss [5]. The penetration of water in sandstones causes mechanical stresses due to swelling of clay minerals causing differential pressures. Water transports soluble salts and impurities that can crystallize, putting pressure on pore walls. The water absorption properties of the stone can be used to

1559-128X/13/143387-07\$15.00/0

(C) 2013 Optical Society of America predict the vulnerability to this common decay mechanism [4]. Similar mechanical stresses occur as a result of freeze-thaw cycles acting on stone materials [4]. The availability of water and soluble nutrients also encourages the growth of organisms responsible for biodeterioration [6]. Water absorption properties of rocks have been used for some time as durability estimators of stone and building materials [7]. Liquid invasion into the porous network is controlled by material properties, such as porosity and pore size distribution. Hydraulic conductivity is the velocity of the wetting front and describes the ease with which water can move though the pore spaces of a material.

Several methods have been used for in situ measurement of water ingress into stone for stone conservation applications. Water absorption tube testing, such as RILEM test method 11.4, is a simple method used to evaluate the water absorption of a porous material. When a water column is applied on a porous material, the water volume absorbed after a definite time is a characteristic of the material. The technique provides a bulk measurement of the rate of water penetration but cannot identify variations in depth from the surface, so it cannot detect 
early stages of deterioration at the stone surface before it progresses to the interior of the stone.

Electrical resistivity methods [8] have been used to profile moisture ingress and distribution, by measuring the resistance between two points attached or tapped in to the surface of the object. The technique is based on the concept that the electrical resistance of a material will decrease when water is present. The quantitative estimation of water content from resistivity measurement is less reliable because of the potentially disruptive influence of dissolved salts, and the use of probes may influence the absorption of water at the surface and limits the technique to centimeter scale resolution.

Nuclear magnetic resonance can be used to investigate the presence and flow behavior of water within saturated porous materials, but it in general requires orders of magnitude longer measurement times and has much lower resolution, especially for in situ measurements [9]. It is not suited to monitoring transient events in situ.

The increasing emphasis on nondestructive testing in conservation and the demand for thorough characterization of materials in situ can be met through the application of portable diagnostic methods, such as optical coherence tomography (OCT). OCT is a fast scanning Michelson interferometer that can measure backscattered light at each depth position within the sample to produce "virtual" cross-sectional images of the surface and subsurface noninvasively. It was designed for noninvasive examination of the interior of the eye and the subsurface structure of biological tissues [10]. The technique has successfully been used to produce cross-sectional images of paintings and museum artifacts in situ [11-16] and has been used to investigate changes in the scattering properties of a geological material, such as jade due to natural and artificial aging $[\underline{17}, \underline{18}]$.

The use of OCT for investigation of water within porous materials is based on the fact that as water displaces air in the porous network of the sample it reduces refractive index mismatch. Water has a refractive index (RI) of 1.33 (c.f. air refractive index of 1) closer to quartz (RI of 1.54), the primary constituent of the sandstone samples. The effect of this is to reduce scattering within the sample and decrease the pixel intensity values of the image. Optical clearing is a well-known technique in OCT imaging of biological tissues $[19,20]$. OCT produces noninvasive and nondestructive depth resolved quantification of hydraulic conductivity in sandstones and other porous materials to determine vulnerability of the material to weathering. This is analogous to OCT monitoring of the permeability coefficient of aqueous glucose solution in biological tissues $[20,21]$.

\section{Materials and Methods}

The instrument used is a portable Thorlabs OCP930SR with a light source operating at a central wavelength of $930 \mathrm{~nm}$ and full width half-maximum (FWHM) bandwidth of $100 \mathrm{~nm}$. The axial resolution is $6.5 \mu \mathrm{m}$ and the lateral resolution is $9 \mu \mathrm{m}$. The OCT probe consists of the Michelson interferometer and an objective lens with a numerical aperture of 0.06 . A piezoelectric scanning mirror within the OCT probe enables rapid scanning in the transverse direction. The OCT is a Fourier domain OCT where the reference mirror is stationary and the interference signal is collected as a function of wavelength through a spectrometer [22]. The interference spectrum is then resampled into uniform $k$ space, tapered with a Hann window and Fourier transformed to obtain the depth resolved structure of the sample. The pixel intensity at a point in the image corresponds to the strength of the backscattered light from that point inside the object.

The instrument has been used for the in situ examination of paintings and cultural heritage materials [15].

A. Samples

1. Sintered Disks

Sintered disks are porous filtration disks composed of quartz glass granules that have been fused together. They were selected as porous materials with a similar refractive index as sandstone to model the technique with the simplification of a single component material and homogeneous structure. Disks of two different pore size ranges (grade 3: $5-15 \mu \mathrm{m}$, grade 4: 1-2 $\mu \mathrm{m}$ ), comparable to the pore size distributions occurring in natural sandstones, were investigated.

\section{Sandstone}

The two selected materials were collected from the sites of rock art panels at Weetwood Moor (WM) and Chatton Park (CP) in Northeast England. The samples were loose cairn stones from the area of the rock art panels and considered by visual inspection of color, grain size, and composition to be lithologically representative of the panels. The sandstone samples were fine grained with a mean pore size of $2 \mu \mathrm{m}$ (WM) and medium grained with a mean pore size of $5 \mu \mathrm{m}$ (CP). These pore sizes were found from mercury intrusion porosimetry (MIP) [23].

\section{B. Measurement Procedure}

Measurements were made at a distance of $10 \mathrm{~mm}$ from the imbibition point at the sample surface (Fig. 1). Water is added at a rate to ensure that a surface droplet is on the sample throughout the experiment, thus matching supply to imbibition and

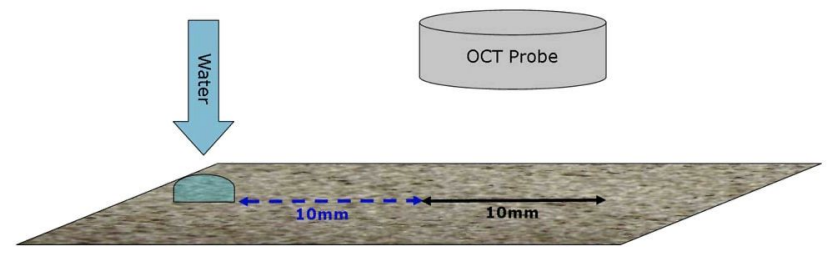

Fig. 1. Schematic of measurement procedure: water is added $10 \mathrm{~mm}$ away from the $10 \mathrm{~mm}$ lateral range of the scan to allow water to penetrate through the depth of the sample before spreading laterally by capillary action. 
preventing water flooding across the sample surface. Measurements were also performed with the samples in a vertical position with water added below the observed range to investigate the influence of gravity on wetting.

OCT images monitoring a $10 \mathrm{~mm}$ transverse range at 1.14 frames per second continuously for the duration of the experiment were recorded with the probe stationary. Each virtual cross section (B scan) is produced from 1000 depth profiles (A scan), giving an image size of $10 \mathrm{~mm}$ by $1.6 \mathrm{~mm}$. The technique provides depth resolved measurement but with limited penetration depth into the sample due to the level of scattering; the effect of water can only be registered to a depth of $\sim 1 \mathrm{~mm}$ depending on the material.

The image acquisition speed of the instrument was set appropriate to requirements of the application, optimizing the signal to noise ratio within the time scale of the wetting process investigated. Unlike biomedical imaging applications where fast imaging speeds are required to reduce motion artifact, in this case the imaging speed required is determined by the time taken for water to travel across the $10 \mathrm{~mm}$ range of the sample under observation. This allows for slower imaging to increase the signal to noise ratio to improve the detection of changes in the scattering properties of the sample due to the presence of water. With the set image acquisition time of $0.88 \mathrm{~s}$ per frame (B scan), if the wetting front moves across the $10 \mathrm{~mm}$ range within a single image frame, its velocity is above $1 \mathrm{~cm} \mathrm{~s}^{-1}$ and can therefore be considered to be permeable with regard to hydraulic conductivity [23]. In a $2 \mathrm{~h}$ observation time under these settings and taking $0.1 \mathrm{~mm}$ (10 columns of A scans) as the minimum distance range of detectable water movement, wetting velocities down to $10^{-6} \mathrm{~cm} \mathrm{~s}^{-1}$ can be measured; that is, the stone can be considered impervious to water. The full range of hydraulic conductivities that are likely to occur in natural sandstones $\left(10^{-6}\right.$ to $1 \mathrm{~cm} \mathrm{~s}^{-1}$ ) can be detected by this imaging speed.

Virtual cross sectional images of the WM sandstone sample are shown in Fig. 2 when dry and wet. The presence of water in the sample will reduce scattering as it reduces refractive index mismatch; consequently features can be seen to a greater depth within the sample. Water acts as a clearing agent for sandstone. The stack of cross-sectional images over time can be displayed as an $(x, z, t)$ image cube as shown in Fig. 3. Pixel intensity values across a single row representing a specific depth were extracted
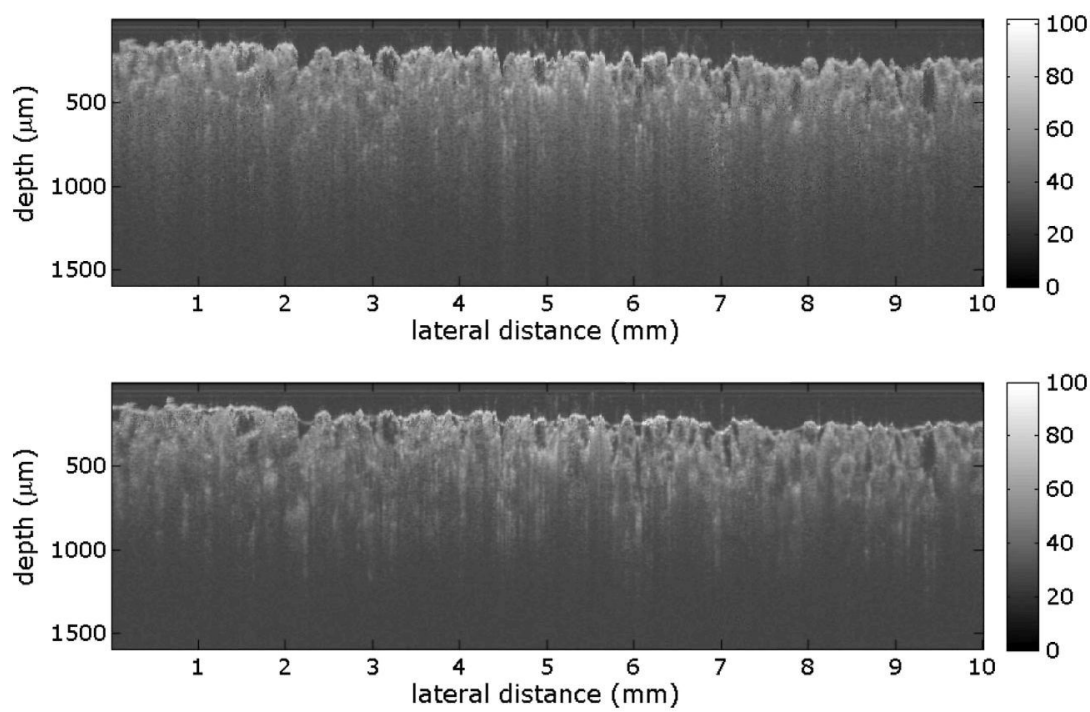

Fig. 2. OCT virtual cross sections of WM sandstone sample when (a) dry and (b) wet (see Media 1 and Media 2).

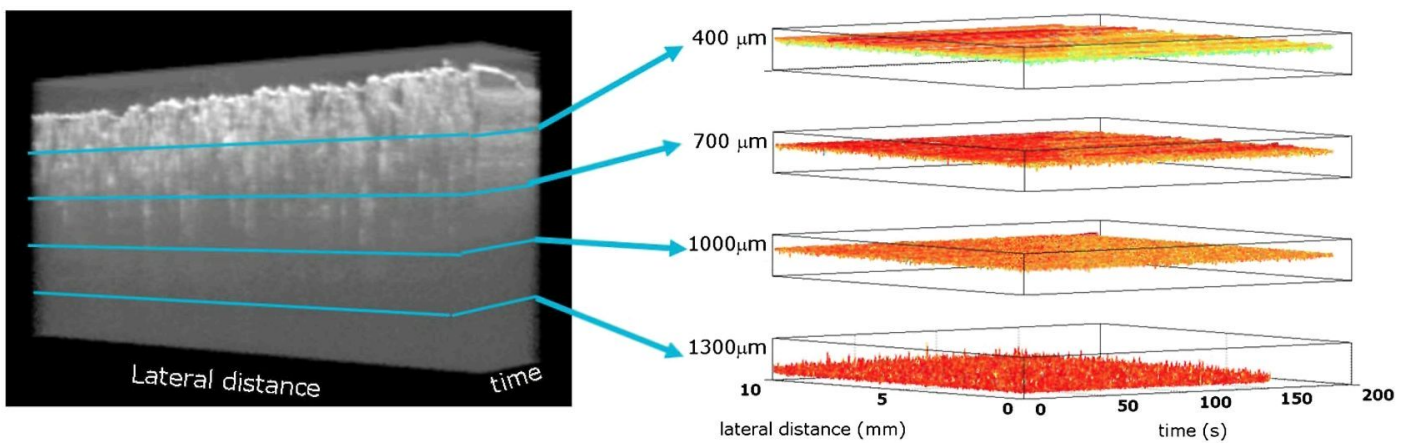

Fig. 3. Stack of OCT virtual cross sections as a function of time displayed as a ( $x, z$, time) image cube from which depth "slices" ( $x$, time) can be extracted. 
from each cross section in MATLAB over the duration of the measurement to create a matrix of pixel intensity values at a specific depth over time.

\section{Results and Discussion}

Figures $\underline{4}$ and $\underline{5}$ show the decrease in the pixel intensity values due to the reduction of scattering in the two sintered disks caused by the presence of water in the pore network. In Figs. 4(a) and 5(a), depth scan intensity values were averaged across the $10 \mathrm{~mm}$ lateral range of the cross sections for both a wet

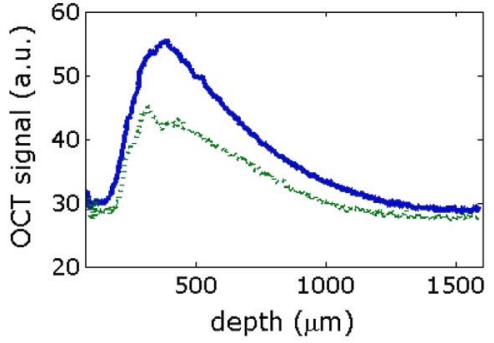

(a)

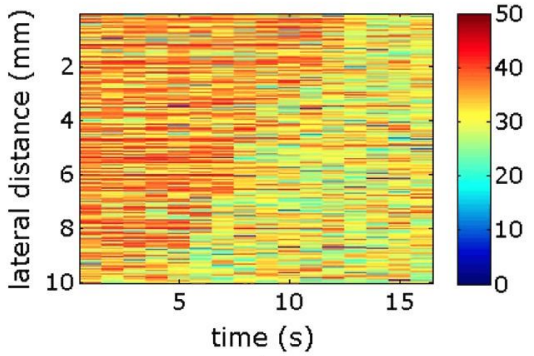

(c) and a dry sample. The initial peak centered at approximately $250-300 \mu \mathrm{m}$ is due to scattering at the surface of a sample. There is a slight shift in the peak position for the dry and wet samples in Fig. 4(a) because a film of water was formed at the rock surface due to capillary action. The rougher surfaces due to the larger glass particles of the $5-15 \mu \mathrm{m}$ pore range sintered disk results in a broader peak [Fig. 4(a)] compared to Fig. 5(a) where the smooth surface of the 1-2 $\mu \mathrm{m}$ pore diameter disk gives a sharper peak. Pixel intensity values decreased more significantly

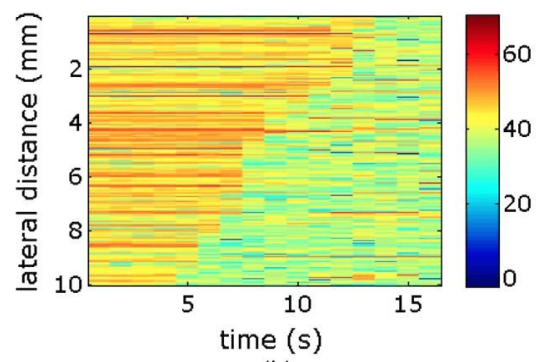

(b)

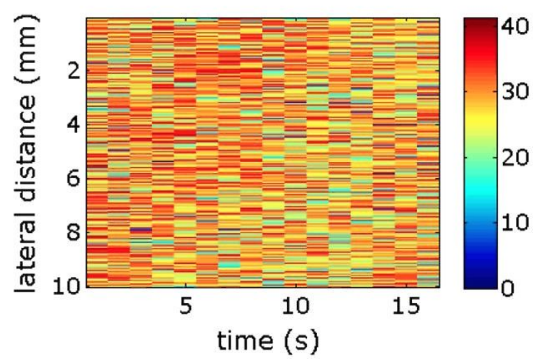

(d)

Fig. 4. Sintered disk grade $3(\mathbf{5 - 1 5} \mu \mathrm{m}$ pore size): (a) pixel intensity values averaged across the $10 \mathrm{~mm}$ cross section when dry (solid blue line) and wet (dotted green line); signal intensity values at depths of (b) $\sim 400 \mu \mathrm{m}$, (c) $\sim 700 \mu \mathrm{m}$, and (d) $\sim 1000 \mu \mathrm{m}$ across the lateral range of the scan over time. The OCT signals are in log scales.

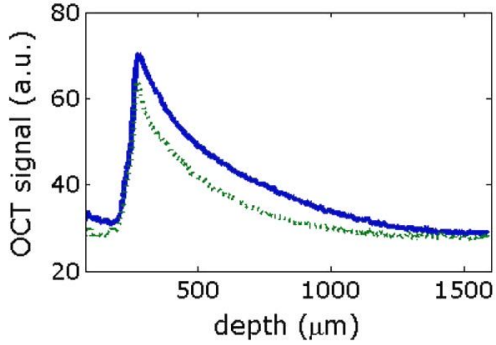

(a)

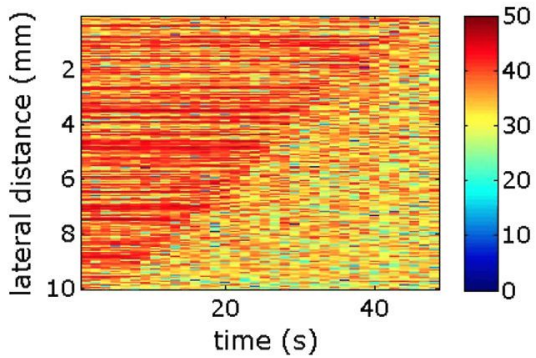

(c)

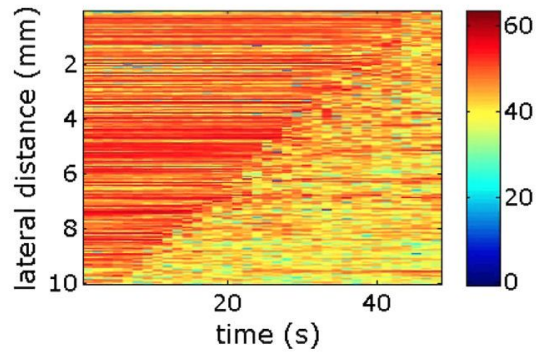

(b)

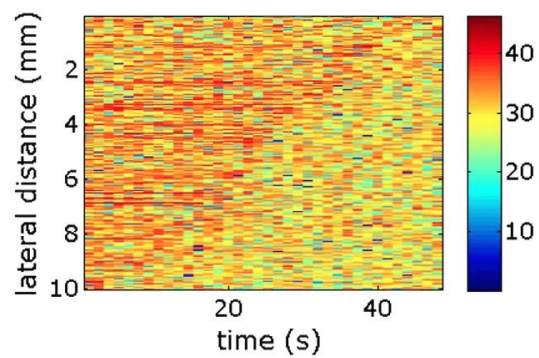

(d)

Fig. 5. Sintered disk grade $4(1-2 \mu \mathrm{m}$ pore size): (a) pixel intensity values averaged across the $10 \mathrm{~mm}$ cross section when dry (solid blue line) and wet (dotted green line), signal intensity values at depths of $(b) \sim 400 \mu \mathrm{m},(\mathrm{c}) \sim 700 \mu \mathrm{m}$, and (d) $\sim 1000 \mu \mathrm{m}$ across the lateral range of the scan over time. The OCT signals are in $\log$ scales. 


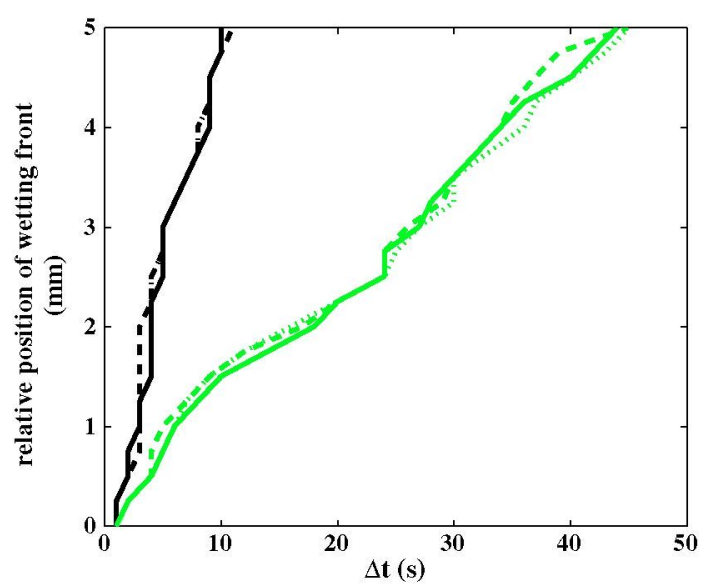

Fig. 6. Position of the wetting front over time for sintered disks with $5-15 \mu \mathrm{m}$ pore size range (black lines) and $1-2 \mu \mathrm{m}$ pore size range (green lines) shown at depths of $\sim 400 \mu \mathrm{m}$ (solid line), $\sim 700 \mu \mathrm{m}$ (dashed line), and $\sim 1000 \mu \mathrm{m}$ (dotted line) into the sample.

for the 5-15 $\mu \mathrm{m}$ pore diameter sintered disk than the 1-2 $\mu \mathrm{m}$ pore diameter disk across the image irrespective of depth until the effects of water can no longer be detected at approximately $1 \mathrm{~mm}$. The $(x, z, t) \mathrm{im}-$ age cube is then resliced in MATLAB to show depth resolved changes over time [Figs. $\underline{4(b)}-\underline{4(d)}$ and $\underline{5(b)}$ $5(\mathrm{~d})]$. The wetting front can be seen moving across the lateral distance of the scan with time at different depths within the sample to identify any changes within the properties of the sample with depth from the surface. Pixel rows were selected at different depths within the sample and are shown for depths of $\sim 400 \mu \mathrm{m}, \sim 700 \mu \mathrm{m}$, and $\sim 1000 \mu \mathrm{m}$ across the lateral range of the scan over time for sintered disks with a pore diameter range of $5-15 \mu \mathrm{m}$ in Fig. $\underline{4}$ and 1-2 $\mu \mathrm{m}$ in Fig. 5. In Figs. 4(b)-4(d) water enters at $3 \mathrm{~s}$ at $10 \mathrm{~mm}$ and crosses the lateral range to $0 \mathrm{~mm}$ at $14 \mathrm{~s}$, and in Figs. 5(b) $-5(\mathrm{~d})$ it enters at $3 \mathrm{~s}$ and crosses the lateral range by $44 \mathrm{~s}$, showing little difference in water movement speed in the lateral direction between the different depths.

The hydraulic conductivity is given by the velocity of the wetting front. Figure 6 shows that the hydraulic conductivity of the sintered disk with $5-15 \mu \mathrm{m}$ pores is $\sim 4$ times as high as the one with the 1-2 $\mu \mathrm{m}$ pores.

Figures $\underline{7}$ and $\underline{8}$ show that the pixel intensity values decreased for the WM sandstone and the CP sandstone due to water penetration across the image irrespective of depth until the effects of water can no longer be detected at approximately $1 \mathrm{~mm}$ in the sandstone samples. The depth penetration of the technique is similar for both sandstone samples. The initial peak centered at approximately 200 $250 \mu \mathrm{m}$ on each plot is due to scattering at the surface of the sample. Figures $7(\mathrm{~b})-7(\mathrm{~d})$ and $8(\mathrm{~b})-8(\mathrm{~d})$ sample the signal intensity at a specific depth of 400,700 , and $1000 \mu \mathrm{m}$ over the duration of the measurement, and there is no depth dependent difference in hydraulic conductivity in the WM and CP samples. In Figs. $7(\mathrm{~b})-7(\mathrm{~d})$ water enters at $25 \mathrm{~s}$ at $10 \mathrm{~mm}$ and crosses the lateral range to $0 \mathrm{~mm}$ at $127 \mathrm{~s}$ and in Figs. $\underline{8(\mathrm{~b})}-8(\mathrm{~d})$ it enters at $10 \mathrm{~s}$ and crosses the lateral range by $51 \mathrm{~s}$, showing little difference in water movement speed in the lateral direction between the different depths. The change in signal due to water cannot be detected beyond $1 \mathrm{~mm}$.

For the sintered disk samples, the hydraulic conductivity showed no depth dependency as was expected with the structurally and compositionally homogeneous materials. The velocity of the wetting

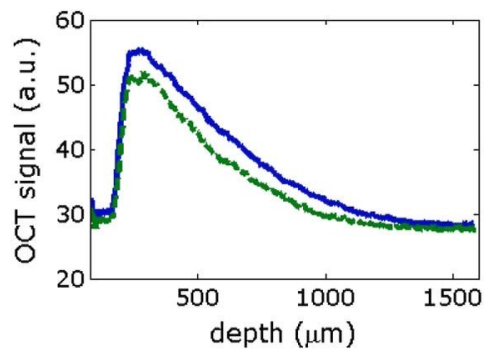

(a)

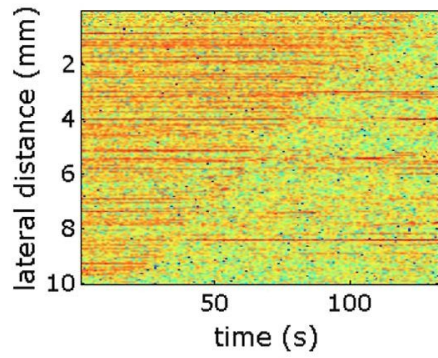

(c)

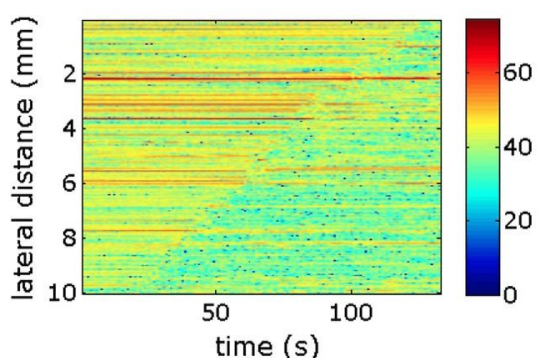

(b)

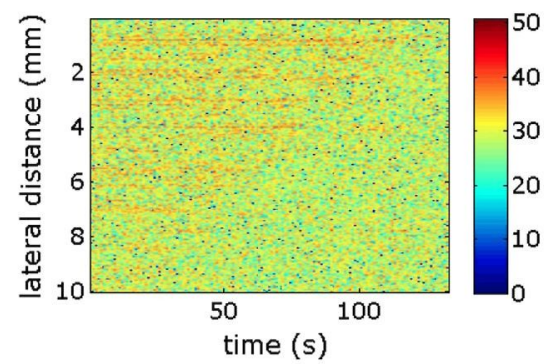

(d)

Fig. 7. WM sandstone sample: (a) pixel intensity values averaged across the $10 \mathrm{~mm}$ cross section when dry (solid blue line) and wet (dotted green line), signal intensity values at depths of (b) $\sim 400 \mu \mathrm{m},(\mathrm{c}) \sim 700 \mu \mathrm{m}$, and (d) $\sim 1000 \mu \mathrm{m}$ across the lateral range of the scan over time. The OCT signals are in log scales. 


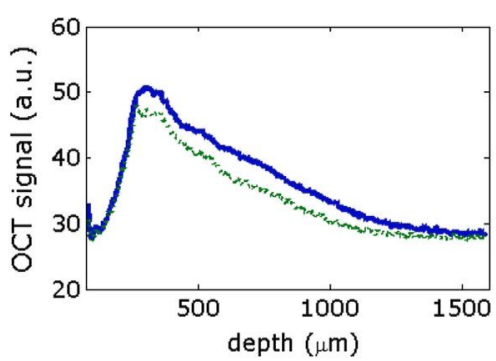

(a)

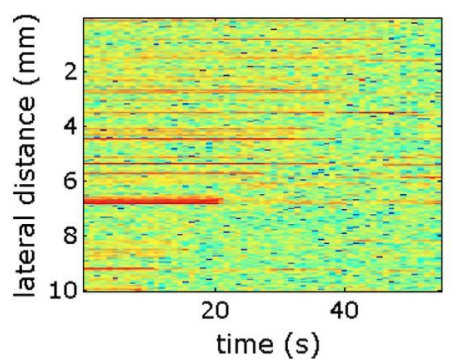

(c)

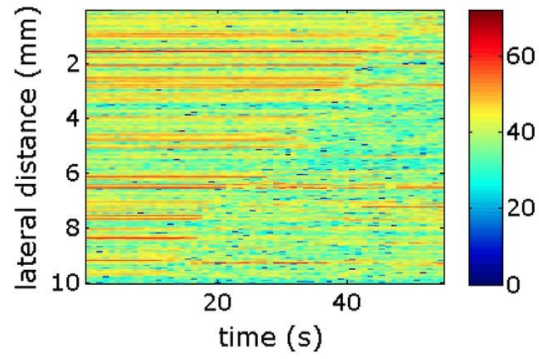

(b)
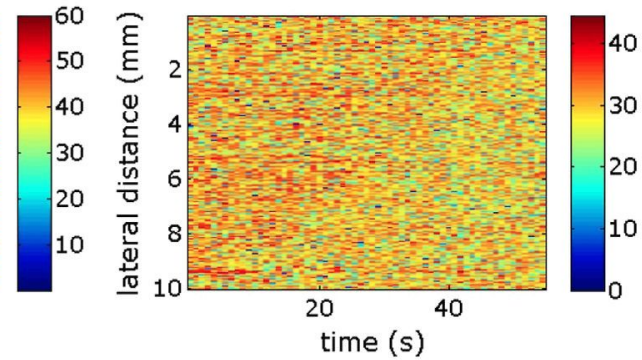

(d)

Fig. 8. CP sandstone sample: (a) pixel intensity values averaged across the $10 \mathrm{~mm}$ cross section when dry (solid blue line) and wet (dotted green line), signal intensity values at depths of $(b) \sim 400 \mu \mathrm{m},(\mathrm{c}) \sim 700 \mu \mathrm{m}$, and (d) $\sim 1000 \mu \mathrm{m}$ across the lateral range of the scan over time. The OCT signals are in $\log$ scales.

front is constant across the observed time range. Sintered disks with pore diameters of $5-15 \mu \mathrm{m}$ show a wetting front velocity of $0.091 \pm 0.005 \mathrm{~cm} \mathrm{~s}^{-1}$ and can be considered pervious. Sintered disks with pore diameters of 1-2 $\mu \mathrm{m}$ show hydraulic conductivities $0.024 \pm 0.001 \mathrm{~cm} \mathrm{~s}^{-1}$ and are pervious to semipervious. Figure 9 shows that the wetting front velocities for sandstone samples were $0.024 \pm 0.001 \mathrm{~cm} \mathrm{~s}^{-1}$ for CP (mean pore size $5 \mu \mathrm{m}$ ) and $0.0098 \pm$ $0.0005 \mathrm{~cm} \mathrm{~s}^{-1}$ for WM (mean pore size $2 \mu \mathrm{m}$ ). Both are semi-pervious with the CP sample bordering on pervious. The values are in the expected range for sandstones [23]. Hydraulic conductivities found in this study for WM and CP sandstone samples are

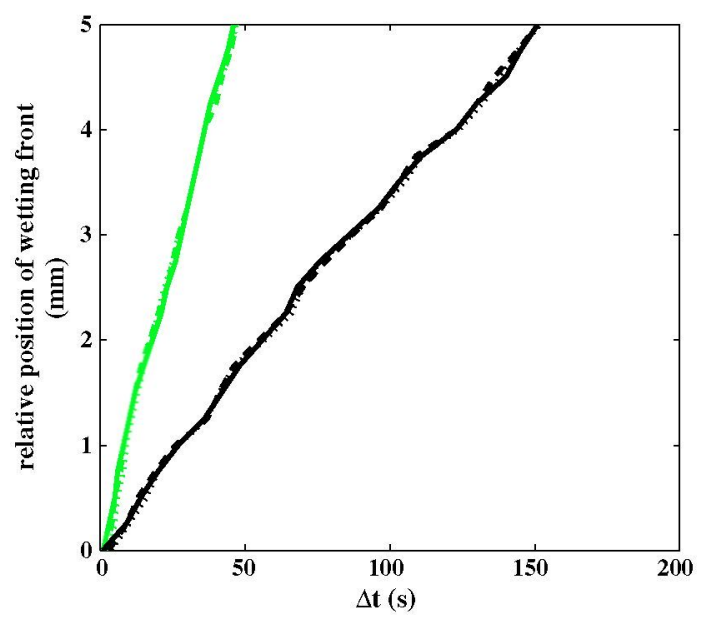

Fig. 9. Position of the wetting front over time for WM (black lines) and $\mathrm{CP}$ (green lines) sandstone samples shown at depths of $\sim 400 \mu \mathrm{m}$ (solid line), $\sim 700 \mu \mathrm{m}$ (dashed line), and $\sim 1000 \mu \mathrm{m}$ (dotted line) into the sample. qualitatively consistent with permeability values found from MIP investigations of the samples. MIP measures the mercury injection pressure through a rock sample, and the pore size distribution is then derived from the relationship between minimum pore neck size and mercury injection pressure [23]. Permeability derived from MIP measurements relies on the determination of the characteristic pore size and the critical pressure at which mercury spans the sample and is a property of the rock derived from the measured microstructural length scale of a rock [24]. In contrast, hydraulic conductivity measured in this paper depends not only on the intrinsic permeability but also the level of water saturation of the rock. It is therefore difficult to quantitatively compare directly the MIP derived permeability (in units of area) and the OCT measured hydraulic conductivity (in units of speed). In OCT applications to biological tissues, fluid flow rate is often quoted as a permeability coefficient $[20,21]$, which is not the same as the intrinsic permeability described above.

Hydraulic conductivity measurements with OCT taken with samples in a vertical position showed that wetting front velocities for sandstone samples were $0.024 \pm 0.001 \mathrm{~cm} \mathrm{~s}^{-1}$ for CP and $0.0098 \pm$ $0.0005 \mathrm{~cm} \mathrm{~s}^{-1}$ for WM, which are the same as their corresponding values for horizontal hydraulic conductivity, indicating that material properties dominate the movement of water in the samples rather than gravity.

The OCT has recently been taken to the field to measure the hydraulic conductivity of gravestones in various states of weathering, demonstrating the ease at which the technique can be used for in situ measurements. 


\section{Conclusion}

This study demonstrates the capability of OCT to register the movement of water through the porous network of dry samples to measure the depth resolved hydraulic conductivity of materials. Water acts as a clearing agent for OCT imaging of sandstone. The difference in pixel intensity values between dry and wet samples is shown to be an effective parameter with which to register the position of the wetting front. For this application, the image acquisition speed was set at 1.14 frames per second, enabling the technique to detect wetting front velocities from $1 \mathrm{~cm} \mathrm{~s}^{-1}$ to $10^{-6} \mathrm{~cm} \mathrm{~s}^{-1}$ covering the full range of hydraulic conductivities likely to occur in natural sandstone from pervious to impervious within a $2 \mathrm{~h}$ observation time.

The technique has the potential to monitor changes due to weathering over time and to determine depth penetration of conservation treatments and the effect of water proofing treatments on building and cultural heritage materials in situ.

This research project is jointly funded by the UK Arts and Humanities Research Council, and the Engineering and Physical Sciences Research Council through the Science and Heritage Programme (www .heritagescience.ac.uk) and the English Heritage.

\section{References}

1. E. Doehne and C. A. Price, Stone Conservation an Overview of Current Research (Getty Conservation Institute, 2010).

2. H. Siedel, S. Pfefferkorn, E. Plehwe-Leisen, and H. Leisen, "Sandstone weathering in tropical climate: results for lowdestructive investigations at the temple of Angkor Wat, Cambodia," Eng. Geol. 115, 182-192 (2010).

3. B. Fitzner, K. Heinrichs, and D. La Bouchardiere, "Weathering damage on Pharonic sandstone monuments in Luxor-Egypt," Build. Environ. 38, 1089-1103 (2003).

4. A. V. Turkington and T. R. Paradise, "Sandstone weathering: a century of research and innovation," Geomorphology 67 , 229-253 (2005).

5. R. A. L. Wray, "A global review of solutional weathering forms on quartz sandstones," Earth-Sci. Rev. 42, 137-160 (1997).

6. Th. Warscheid and J. Braams, "Biodeterioration of stone: a review," Int. Biodeterior. Biodegrad. 46, 343-368 (2000).

7. E. Molina, G. Cultrone, E. Sebastian, F. J. Alonso, L. Carrizo, J. Gisbert, and O. Buj, "The pore system of sedimentary rocks as a key factor in the durability of building materials," Eng. Geol. 118, 110-121 (2011).

8. O. Sass and H. A. Viles, "Wetting and drying of masonry walls: 2D-resistivity monitoring of driving rain experiments on historic stonework in Oxford, UK," J. Appl. Geophys. 70, 72-83 (2010).

9. A. T. Watson and C. T. P. Chang, "Characterizing porous media with NMR methods," Prog. Nucl. Magn. Reson. Spectrosc. 31, 343-386 (1997).

10. D. Huang, E. A. Swanson, C. P. Lin, J. S. Schuman, W. G Stinson, W. Chang, M. R. Hee, T. Flotte, K. Gregory, C. A Puliafito, and J. G. Fujimoto, "Optical coherence tomography," Science 254, 1178-1181 (1991).

11. P. Targowski, B. Rouba, M. Wojtkowski, and A. Kowalczyk, "Application of optical coherence tomography to nondestructive examination of museum objects," Stud. Conserv. 49, 107-114 (2004).

12. H. Liang, R. Cucu, G. M. Dobre, D. A. Jackson, J. Pedro, C. Pannell, D. Saunders, and A. G. Podoleanu, "Application of OCT to examination of easel paintings," Proc. SPIE 5502, 378 (2004).

13. H. Liang, M. Cid, R. Cucu, G. Dobre, A. Podoleanu, J. Pedro, and D. Saunders, "En-face optical coherence tomography-a novel application of non-invasive imaging to art conservation," Opt. Express 13, 6133-6144 (2005).

14. P. Targowski and M. Iwanicka, "Optical coherence tomography: its role in the non-invasive structural examination and conservation of cultural heritage objects-a review," Appl. Phys. A 106, 265-277 (2012).

15. H. Liang, B. Peric, M. Hughes, A. Podoleanu, M. Spring, and S. Roehrs, "Optical coherence tomography in archaeology and conservation science-a new emerging field," Proc. SPIE 7139, 713915 (2008).

16. URL: http://www.oct4art.eu.

17. M. L. Yang, C. W. Lu, I. J. Hsu, and C. C. Yang, "The use of optical coherence tomography for monitoring the subsurface morphologies of archaic jades," Archaeometry 46, 171-182 (2004).

18. S. Chang, Y. Mao, G. Chang, and C. Flueraru, "Jade detection and analysis based on optical coherence tomography images," Opt. Eng. 49, 063602 (2010).

19. M. Kinnunen, R. Myllylä, and S. Vainio, "Detecting glucoseinduced changes in vitro and in vivo experiments with optical coherence tomography," J. Biomed. Opt. 13, 021111 (2008).

20. M. G. Ghosn, E. F. Carbajal, and N. A. Befrui, "Differential permeability rate and percent clearing of glucose in different regions in rabbit sclera," J. Biomed. Opt. 13, 021110 (2008).

21. H. Xiong, Z. Guo, C. Zeng, L. Wang, Y. He, and S. Liu, "Application of hyperosmotic agent to determine gastric cancer with optical coherence tomography ex vivo in mice," J. Biomed. Opt. 14, 024029 (2009).

22. A. F. Fercher, C. K. Hizenberger, G. Kamp, and S. Y. El-Zaiat, "Measurement of intraocular distances by backscattering spectral interferometry," Opt. Commun. 117, 43-48 (1995).

23. J. Bear, Dynamics of Fluids in Porous Media (Dover Publications, 1972).

24. A. J. Katz and A. H. Thompson, "Quantitative prediction of permeability in porous rock," Phys. Rev. B 34, 8179-8181 (1986). 